\title{
ARTÍCULOS
}

\author{
MAREK BARAN
}

Universidad de Łódź

\section{LA SUBJETIVIZACIÓN Y LAS DINÁMICAS INTERACCIONALES}

\begin{abstract}
Marek Baran, La subjetivización y las dinámicas interaccionales [Subjectification and interactional dynamics], Studia Romanica Posnaniensia, Adam Mickiewicz University Press, Poznań, vol. XLI/1: 2014, pp. 3-16. ISBN 978-83-232-2673-4. ISSN 0137-2475. eISSN 2084-4158. Doi: 10.7169/ strop2014.411.001.

In the present article the subjectification process is being discussed in relation to the concept of interactional dynamics. It is suggested that to encode various semantic-pragmatic profiles can lead to changes at the level of communicative behavior patterns, which, for their part, are dominated by a particular order of socio-cultural conventionalization. The scope of conversational markers or nominal forms of address (NFA), which are submitted for analysis in the present study, indicates that the routinizing language use, together with an explicit grammatical manifestation, covers areas that appear to be semantically and pragmatically important in a given speaking community.
\end{abstract}

Keyw ords: Subjectification, Pragmaticalization, Interactional Linguistics, Conversational Markers, Ethnolects, Spanish Language, Face-Work

\section{EN BUSCA DEL MARCO INTERPRETATIVO. INTERSUBJETIVIDAD VS INTERACCIONISMO LINGÜÍSTICO}

El punto de partida de mis reflexiones está arraigado en el uso sociolingüístico y la situación discursiva, en la dinámica de los intercambios verbales, la producción verbal, el análisis de los actos de habla, así como en la sociolingüística de las relaciones interpersonales y la lógica de los sistemas simbólicos estudiados en relación con los rituales sociales. Me sitúo, de este modo, en los acercamientos interaccionales que conciben los procesos verbales efectivamente a través de su carácter interactivo: cualquier enunciado, sea cual sea su grado de complejidad, no aparece nunca como resultado de un solo interlocutor, sino que es siempre fruto de un proceso interactivo en el que la dualidad (o la multitud) de los emisores, el nivel del encadenamiento de los enunciados en un orden secuencial junto con la coordinación de las acciones 
son elementos que ayudan a entender la actividad verbal. La «gestión comunicativa» o, empleando el término utilizado por Kerbrat-Orecchioni (1996: 14), la «tecnología de la conversación», supone que los interactanes, al cumplir con ciertas obligaciones impuestas la situación y el contexto comunicativos, recurren, de modo sistemático, a determinadas estrategias que les permiten, por ejemplo, asegurar la alternancia de los turnos de habla, llevar a cabo una negociación, estructurar un relato o reparar ciertas deficiencias que pueden producirse a lo largo del acto comunicativo. Además, mencionando el concepto de dinámicas interaccionales, debo remitirme obligatoriamente al «archiprincipio de face-work», definido en el marco de los planteamientos de cortesía verbal por Brown y Levinson (1978; 1987), según el cual los actos de habla emitidos a lo largo de los intercambios comunicativos se conciben siempre en relación con los efectos, negativos o positivos, que estos pueden tener sobre la relación interpersonal ${ }^{1}$. Aunque se trata de un planteamiento bien conocido, me parece importante volver a subrayar que la cortesía, en el enfoque que se extiende a partir de Lakoff, (1973; 1975), Leech (1983) y los ya mencionados Brown y Levinson (1978; 1987), deja de concebirse tan solo como un conjunto de muestras de respeto o deferencia y empieza a considerarse como la necesidad humana de mantener el equilibrio en las relaciones interpersonales y su manifestación externa. Las elecciones de los hablantes, es decir, las elecciones de las formas y mecanismos lingüísticos a través de los cuales se configura la forma y la estructura de los enunciados, o de la actividad discursiva como tal, se someten al Principio de Cortesía que, por su parte, resulta más relevante que el de comunicación informativa y económica. La cortesía verbal, bajo esta óptica, aparece como la motivación principal que impulsa a los sujetos a comportarse lingüísticamente de un modo concreto.

Apoyándome en el interaccionismo lingüístico, concibo, igualmente, las dinámicas interaccionales a través de la «huella» que en los actos comunicativos dejan sus participantes. De esta manera, me acerco al concepto de subjetivización que, de acuerdo con Reynoso Noverón (2005: 80), se percibe como «el acto lingüístico mediante el cual el hablante, conceptualizador de la escena discursiva, ubica el lugar que quiere ocupar dentro de dicha escena, con respecto de las otras entidades participantes (interlocutor, objeto de la enunciación) y, con ello, establece relaciones de tipo jerárquico al interior de cada acto comunicativo, con intenciones pragmáticas de determinado tipo». El término «huella» no se presenta, en este caso, solamente como una referencia de tipo metafórico. De hecho, se trata de la denominación motivada por el término inglés speaker's imprint, propuesto por Finegan (1995: 1), con la cual se apunta hacia la importancia que en el discurso tiene la expresión de la perspectiva o del punto de vista del hablante. Tomando en cuenta la perspectiva de estudio dominante, podría

${ }^{1}$ Me refiero, obviamente, a la regla de valorización de las imágenes, positiva o negativa, de los hablantes; imágenes que, ante todo si tomamos en cuenta la variación intercultural, pueden percibirse no solo en función de los «intereses individuales» sino también en función de los «intereses de grupo». 
precisarse que la subjetivización puede contemplarse fundamentalmente en dos direcciones: la primera (a la que daré prioridad en este estudio) ve en la subjetivización un acto que se actualiza en los intercambios comunicativos y que da cuenta de la toma de posición de los hablantes, la cual podría asociarse con el nivel de involucramiento ${ }^{2}$ en la escena discursiva (para algunos, se trataría, en este caso, de la subjetividad lingüística). Otros planteamientos ${ }^{3}$ amplían dicha perspectiva, concibiendo la subjetivización fundamentalmente como un proceso diacrónico en el que los significados van gramaticalizándose, reflejando cada vez más las creencias o las actitudes subjetivas de los hablantes hacia las proposiciones. En este sentido, la subjetivización contribuye a la modificación de los patrones sintácticos o estructurales y conlleva una serie de restricciones en el comportamiento proposicional entre ellas: el debilitamiento, e incluso cancelación, de la capacidad sintáctica normal (modificación, expansión, complementación, etc. $)^{4}$.

Los estudios centrados en las consecuencias sintácticas de la subjetivización (o en el tipo de cambio lingüístico que esta supone) establecen determinados patrones o pautas de lexicalización y gramaticalización, admitiendo, al mismo tiempo, que la codificación o la manifestación gramatical explícita abarca aquellas zonas de uso que se presentan como semántica y pragmáticamente importantes en una determinada comunidad lingüística. Desde el punto de vista sincrónico, puede apreciarse, además, la interrelación entre la estructuración gramatical y la variación lingüística, como también la vinculación de la organización sintáctica con la organización conceptual de los hablantes (Company Company, 2002: 43). Los distintos modelos de lexicalización o gramaticalización pueden manifestarse no solamente en el nivel formal, es decir, en el nivel de distintas construcciones estructurales ${ }^{5}$ que cobran mayor o menor protagonismo en una comunidad dada, sino también en el nivel de selección de contextos o frecuencias de uso de las formas que funcionan en diferentes comunidades lingüísticas. En el ámbito hispánico, se han estudiado, por ejemplo, los mismos espacios categoriales que sufrieron distintos procesos de gramaticalización, conduciendo así a distintas codificaciones de una misma área funcional. Me refiero a los ya bien conocidos estudios de Company Company (2002), quien ha tratado de demostrar que en el español peninsular y en el español de México la posesión nominal (en particular, las duplicaciones posesivas), el comportamiento de los diminutivos, el funcionamiento del leísmo y el uso del pretérito perfecto compuesto corresponden a una diferente selección de rasgos semánticos o, en otros términos, a un diferente «perfilamiento»

${ }^{2}$ Concepto que corresponde en líneas generales a la noción de involvement desarrollada en las corrientes interaccionales, entre otros, por Daneš (1994) y Tannen (1989).

3 Véanse, en este sentido, los trabajos de Langacker (1987, 1990, 1991); de Traugott (1989, 1995, 1999) o de Traugott y Dasher (2001).

4 Para más detalle sobre esta cuestión, véase Traugott y Dasher (2001).

5 En la terminología de Company Company (2002: 40), «nivel de codificaciones formales externas»». 
que se opera en cada una de las variedades mencionadas. En la opinión de la autora, el español de España sería «más sensible a las características referenciales de las entidades en juego, esto es, a las propiedades semánticas observables de las entidades», mientras que el español de México sería «más sensible a las valoraciones que el hablante realice sobre estas entidades y a las relaciones que estas entidades pueden contraer dentro del discurso» (Company Company, 2002: 44). En otras palabras, el español peninsular seguiría «una semántica de tipo referencial» y el español mexicano, en cambio, se pronunciaría por «una semántica de tipo relacional» (Company Company, 2002: 44). Dos patrones distintos de lexicalización corresponderían, en este caso, a dos pautas distintas de creación de gramática ${ }^{6}$.

El planteamiento que sugiere la codificación de distintos perfilamientos semántico-pragmáticos, me sirve de inspiración para hablar de las modificaciones a nivel de los patrones de conductas comunicativas que, por su parte, se ven dominadas por un determinado orden de convencionalización socio-cultural. Sostengo, por tanto, que el proceso de subjetivización, tanto en su faceta diacrónica como sincrónica, explica en numerosísimas ocasiones los cambios que se producen en los modelos de interactuación comunicativa, vinculados estos con el estilo de comunicación dominante en una comunidad de habla dada. De igual modo, en el caso de las comparaciones que se efectúan a nivel transcultural, los operadores lingüísticos considerados como equivalentes desde el punto de vista formal (entre ellos, por ejemplo, formas nominales o pronominales de tratamiento, formas diminutivas o marcadores conversacionales) corresponden a perfilamientos distintos, indicando así que, en algunos casos, los hablantes, siguiendo determinadas pautas de orden sociopragmático, están más motiva-

${ }^{6}$ Company Company (2002: 45-68) sostiene que el español de España marca una nítida preferencia por un «perfilamiento absoluto», atendiendo las entidades per se. En el caso de la zona nominal aquello se manifestaría por la duplicación posesiva que tiene casi siempre una función desambiguadora [en el caso del español mexicano, la misma duplicación funcional (tipo: Sus papás de Maru viven en Chapultepec /todas las ejemplificaciones son de Company Company (2002)/) tendría un trasfondo discursivo diferente y señalaría básicamente la perspectiva valorativa del hablante (que indica, por ejemplo, la relevancia que tiene para él el poseedor)]. Tratándose del comportamiento de los diminutivos, el español de México privilegiaría, de nuevo, diversas valoraciones de tipo pragmático que el hablante proyecta sobre las entidades en disminución (Ay, de favorcito haz como que le hablas y verás que en estos momentos, la pelotita entra y jlisto!), mientras que en el caso del español peninsular el valor referencial de disminución del tamaño del referente competiría y predominaría ligeramente sobre los valores no referenciales o pragmáticos. En cuanto al leísmo, la variante mexicana se mostraría más sensible a factores relacionados con la semántica pragmática del evento (entre ellos, el grado de afectividad, valoración y prominencia del objeto), mientras que el leísmo peninsular tomaría en cuenta básicamente los factores referenciales, como el género y número y, en particular, masculinidad e individuación de la entidad objeto. Por su parte, en el caso del empleo del pretérito perfecto compuesto y del pretérito simple, se asignarían valores preferenciales distintos a cada una de estas formas verbales (en México, el pretérito perfecto compuesto indicaría, ante todo, que el evento en cuestión, desde la perspectiva del hablante, sigue teniendo relevancia en el momento de la enunciación). 
dos por su propia relación (apreciativa, valorativa, psicológica,...) con las entidades y los eventos que por las entidades mismas. Por consiguiente, la «involucración» y la «valoración de la escena comunicativa», para retomar los conceptos de Company Company (2002: 55), los cuales no se realizan a menudo ni de un modo similar ni en un grado comparable, derivan de distintas semánticas y pragmáticas subyacentes que resultan ser modificadoras de las codificaciones sintácticas e interactivas. Cada lengua, o mejor dicho, cada comunidad de habla, asigna, así, distintos valores preferenciales a determinadas formas lingüísticas.

\section{MARCADORES CONVERSACIONALES Y LOS PROCESOS DE GRAMATICALIZACIÓN / PRAGMATIZACIÓN / SUBJETIVIZACIÓN}

Al vincular la subjetivización con la lingüística de corte interaccional convendría buscar categorías o mecanismos lingüísticos que demostraran de modo convincente la actualización de un determinado perfilamiento de tipo pragmático y socio-comunicativo. Si nos fijamos, por ejemplo, en la recurrencia con la que en el habla aparecen los llamados «marcadores discursivos», ante todo en su función de «conectores pragmáticos», «articuladores conversacionales» u «operadores de acceso y de vinculación con el interlocutor», puede pensarse, efectivamente, que estamos ante una categoría que une la subjetivización con las dinámicas interaccionales.

Las partículas (como solía denominarse a estos operadores en los planteamientos tradicionales) no tienen una función predicativa, pero desempeñan indudablemente un papel importantísimo dentro de los intercambios comunicativos. Evidentemente, estamos ante una clase muy heterogénea desde el punto de vista categorial, funcional y distribucional $^{7}$, pero en este momento me gustaría subrayar ante todo su funcionalidad interaccional, siendo perfectamente consciente de que son numerosas las funciones de coherencia intrafrástica e interfrástica, desarrolladas, entre otros, en los análisis de índole textual. Alejándome, sin embargo, de la perspectiva argumentativo-textual, la que ve en los marcadores discursivos básicamente señales formulativas [ordenadores de la materia discursiva o partículas de puntuación (= pausas oralizadas)], percibo estos, de acuerdo con la propuesta formulada en Baran (2012), como «marcas de carácter interactivo» que, aunque no inciden en el contenido informativo de los enunciados, determinan en gran medida la naturaleza de los actos de habla sobre los que se realizan y se presentan. Acentúo, de este modo, que los marcadores discursivos de distintas clases no se definen únicamente en relación al emisor, sino también en relación al destinatario, siendo así entidades sintomáticas de ambos interactantes o de elementos a través de los que se señala lo que está en juego en la interacción.

${ }^{7}$ Lo demuestra perfectamente la multitud de denominaciones que reciben (conectores, organizadores, operadores, enlazadores, articuladores de turno, articuladores de actitud, marcadores conversacionales, ...). 
Centrándome en particular en las dinámicas interaccionales, me propongo comprobar cómo las actitudes y las valoraciones de los hablantes ante lo comunicado y ante sus interlocutores encuentran codificación explícita en la gramática. Me pregunto, del mismo modo, cómo ciertas «rutinas conversacionales», «formas prefabricadas», que concuerdan con determinados patrones comunicativo-conversacionales de unas determinadas comunidades de habla, corresponden a los procesos que tradicionalmente se consideraba como «gramaticalización».

Fijándonos en los llamados «marcadores conversacionales interactivos»» tipo venga, vaya, anda, toma descubrimos rápidamente que estamos ante unidades que, aparte de contribuir a efectuar determinadas operaciones lógico-lingüísticas que marcan las relaciones entre los mensajes (función argumentativo-textual), se muestran a menudo como un fenómeno de conexión (o desconexión) socio-afectiva. Lo mismo podría decirse de los tratamientos nominales de carácter fático-apelativo tipo hombre, mujer, hijo/a, chico/a, extremadamente frecuentes en los usos conversacionales de las comunidades hispanohablantes. Son realmente distintas las funcionalidades que son propias de estos operadores lingüísticos ${ }^{9}$; en este lugar, me limitaré tan solo a señalar que, en conjunto, se trata de unidades dotadas de un valor eminentemente interaccional, el cual se deja percibir en la regulación de determinados actos y secuencias de habla entre los participantes de los eventos comunicativos. Dicha regulación tiene mucho que ver con la gestión de las imágenes de los hablantes y puede ser al mismo tiempo un elemento definitorio del perfil de la cortesía verbal que se pone en marcha en cada interacción. Es obvio que en muchos casos estamos ante entidades interjectivo-apelativas que, aunque convencionalizadas y «rutinizadas», participan en la búsqueda de la complicidad o de la coparticipación con el interlocutor ${ }^{10}$.

${ }^{8}$ En la tradición gramatical conocidos también como «imperativos gramaticalizados».

9 Véase, en este sentido, Baran (2010, especialmente los capítulos III y IV). En el caso de los llamados «marcadores pragmáticos interactivos», tipo vamos, vaya, venga, anda se distingue allí, entre otros, la función yusiva o exhortativa, la función de partícula reactiva de protesta, muestra de desagrado o rechazo, la función de palabra autocorrectiva de rectificación o matización restrictiva, la función de palabra autocorrectiva de reformulación, la función de marcador reactivo de aceptación, la función de marcador evaluativo, la función de marcador fático de (pre)cierre de la conversación, la función cognitivo-apreciativa, la función de partícula intensificadora de afirmación y la función exclamativa.

${ }^{10}$ Se trata, además, de entidades que a menudo coactúan en la interacción. A modo de ejemplo cito tres secuencias comunicativas extraídas del CREA que ilustran bien esta llamativa combinación de los marcadores pragmáticos interactivos (que se relacionan entre sí o entran en relación con los denominados vocativos gramaticalizados):

(1) - Anda, guapo, pásate por aqui y te tomas algo, que buena falta te hace.

${ }^{\wedge}$ ¿Y preservativo también?

- ¡Tú eres un guarro! La degeneración española, señoras y señores, no empieza por donde ustedes piensan, sino empieza por aquí, por las emisoras que proporcionan estas cosas, que no sabemos ni para lo que sirven ni para nada. (...).

Radio, Radio Vallecas, Variedades (Canela en Rama), 20/03/91, CREA, 2012. 
Como puede apreciarse, un grupo llamativo de los marcadores discursivos, lo constituyen los operadores que comparten como fuente los verbos de movimiento. Puede sostenerse que la recategorización de las formas verbales desemboca frecuentemente en marcadores discursivos importantes desde el punto de vista de la dinámica conversacional e interpersonal, marcadores en cuyo uso no siempre resulta fácil separar el valor puramente enunciativo o reformulativo y el valor interaccional teñido de matizaciones interjectivas y modales.

Suele afirmarse que las formas verbales tales como vamos, venga, vaya, anda se han reanalizado como marcadores del discurso a través del proceso de gramaticalización ${ }^{11}$ que consistiría, como tal, en un conjunto de procesos mediante los que ciertas formas léxicas o estructuras más complejas, a través de su uso en contextos muy concretos, adquieren una función gramatical, o bien, formas o estructuras ya gramaticales adquieren una función aún más gramatical. La direccionalidad que se desprende de la gramaticalización así entendida indica que la tendencia evolutiva conduce, básicamente, del plano léxico al gramatical. Como sugiere Company Company (2004A: 65), el concepto y el término de gramaticalización puede mantenerse como un macrocambio dinámico (un cambio de cambios) que engloba, por su parte, distintas subclases y procesos. El proceso de gramaticalización que experimentan los verbos de movimiento españoles puede describirse igualmente desde la perspectiva de la subjetivización dado que el cambio lingüístico ante el que nos hallamos conduce a la puesta en relieve de las actitudes y de las valoraciones de los hablantes ante lo comunicado o ante la situación comunicativa en la que se ven implicados los interactantes. La subjetivización se presenta, así, como concepto que forma parte de la teoría de la gramaticalización y que pretende explicar cómo ciertas construcciones convencionalizadas en la gramática de una lengua son resultado de procesos de cambio lingüístico que incorporan a la gramática significados pragmáticos varios que codifican la actitud y valoraciones del hablante ante lo comunicado, tanto su perspectiva o punto de vista personal respecto a las entidades objeto de

(2) - ¿Has mirado en el libro de los sueños lo que significa volar? Según Freud es el deseo sexual.

^ Deseo sexual. Es que, hija, estamos dando lo de Freud y todo es deseo sexual. Todo es deseo sexual. Pero, maja, es que vaya cosa.

Domicilio particular, conversación familiar, Segovia, 19/04/91, (formalidad = baja, audiencia $=$ interlocutor, canal $=$ cara a cara $),$ CREA, 2012.

(3) - Oye, ¿y dónde está tu productor? ¿Dónde está, venga, ¿dónde está?

$\wedge$ Pues...

— ¿Pues qué?

^Por ahí, no sé.

- Pues vaya vaya merengue de productor que tú tienes, hija.

TVE 1, Magacines (¿Pero esto qué es?), 20/10/89, CREA, 2012.

${ }^{11}$ Como ya se ha mencionado, en la tradición gramatical suele utilizarse, por tanto, el término de imperativos gramaticalizados. 
la comunicación, y el enunciado o evento en general ${ }^{12}$, como su interacción y proximidad o distancia, afectiva o social, respecto del oyente ${ }^{13}$ (Company Company, 2004b: 1) ${ }^{14}$. Así pues, el concepto de subjetivización puede resultar bastante iluminador en la medida en que muestra cómo el significado pragmático puede llegar a gramaticalizarse y convertirse, por tanto, en una construcción convencional o casi una rutina en una lengua. Como apunta otra vez Company Company (2004b: 3-4), habría que admitir que la diferencia entre una lectura y significado objetivos y una lectura y significado subjetivos es un asunto gradual y reside en el nivel de involucración que el hablante o conceptualizador tenga en lo comunicado por un enunciado específico. Cabe señalar que el proceso de subjetivización traducido en el enriquecimiento pragmático vía codificación de las valoraciones del hablante va siempre unido al debilitamiento de tipo referencial y relacional. Así pues, la subjetivización supone, por un lado, el debilitamiento del significado referencial etimológico originario, y determinadas consecuencias sintácticas en la estructura del enunciado, por otro.

El debilitamiento del significado referencial etimológico originario, que se traduce en un vaciamiento del significado específico en un grado más o menos avanzado, es un fenómeno que hace posible la dinámica del cambio (las formas se vacían, en algún grado, de su significado referencial o situacional etimológico originario para recargarse de significados (inter)subjetivos pragmáticos). Notemos a este respecto que en el caso de los verbos de movimiento que tratamos, la pérdida del valor semántico originario no tiene que ser absoluta: en los marcadores resultantes de los verbos ir y andar perdura un cierto matiz de movimiento en la medida en que los operadores sirven para introducir una invitación a que el oyente haga un esfuerzo común con el hablante para continuar el hilo de la conversación o a que emprenda un movimiento, sea este de naturaleza verbal, intelectual o incluso físico. Lo demuestra perfectamente el caso de los marcadores vamos o venga empleados en su función de palabra autocorrectiva de rectificación o matización restrictiva, o bien palabra autocorrectiva de reformulación o palabra de valor paragráfico. La reformulación que se lleva a cabo por medio de dichos marcadores tiene las indudables marcas de un acto cooperativo: el hablante que, al principio, expone sus ideas o apreciaciones (buscando a menudo la expresión que considera apropiada y que no puede conseguir), trata de ir precisando de modo que su interlocutor comprenda su esfuerzo, lo siga y, al final, coincida en la posición que se ha tomado frente a lo dicho. La función estructuradora de la información y el valor interaccional se superponen mutuamente ${ }^{15}$. Según

${ }^{12}$ Los llamados significados pragmáticos subjetivos.

${ }^{13}$ Los significados pragmáticos intersubjetivos.

${ }^{14}$ El concepto de subjetivización percibido de esta manera se recubre, en cierto modo, con el de modalidad de la gramática tradicional española. Véase, en este sentido, también a Langacker (2000: 297-315) o Nuyts (2001).

${ }^{15}$ Considérense las siguientes secuencias comunicativas: (1) Ser artista es una especie de lujo casi insultante para el resto de la entidad social. Entonces, pues, si no se tiene, propiamente, vamos, 
Romero Aguilera (2006: 52-53), puede pensarse que mediante un proceso cognitivo de naturaleza metafórica se habría pasado de lo espacial a lo discursivo (la meta y el desplazamiento espaciales etimológicos son sustituidos por un desplazamiento mental y una meta pragmática $)^{16}$.

\section{CONSECUENCIAS DEL PROCESO DE SUBJETIVIZACIÓN}

Algunas de las consecuencias básicas que conlleva el proceso de subjetivización en el nivel sintáctico son, según Company Company (2004bB: 7-8), fijación, aislamiento y autonomía predicativa. Los marcadores de discurso (y, entre ellos, las partículas interjectivas) - la mayoría de ellos portadores de significados pragmáticos (inter) subjetivos - forman expresiones fijas, constituyendo por lo regular predicaciones autónomas, prosódicamente independientes, separadas del contexto circundante por pausas o quiebras entonativas. Recordemos que autores como Traugott y Dasher (2001) señalan que toda subjetivización conlleva un número importante de restricciones en el comportamiento sintáctico de las formas que experimentan este cambio, consistentes en el debilitamiento, e incluso cancelación, de la capacidad sintáctica normal (modificación, expansión, complementación, etc.).

Es interesante indagar, aunque brevemente, en el porqué de la facilidad con la que los verbos de movimiento se prestan al proceso de subjetivización. Pienso que la recategorización que se ha podido observar es posible por tratarse de verbos con un valor semántico muy genérico (no sería el caso de deambular o trasladarse que especifican la naturaleza del movimiento realizado). Además, tal y como observa Company Company (2004a: 44), el verbo constituye en general una categoría deíctica, esto es, «adquiere su valor en el contexto, hecho que facilita que el hablante pueda

y como ya he dicho antes, que quedó muy lejano lo de mis bisabuelos terratenientes, verdad, y en fin, hoy llevamos dos generaciones de retraso en lo económico, pues para salir adelante, había que hacer algo.

SE-9, Mujer de 43 años, Funcionaria. Estudiante de Derecho (formalidad = baja, audiencia = oyente pasivo, canal = cara a cara), sin datos sobre la fecha de producción, CREA, 2012.

(2) - ¿Cuánto va valer be por ce? Porque be es paralelo a... Eso es, aqui tengo tres, uno, uno y este multiplicando por menos dos. ¿Se ve que be por ce sería el desarrollo de un determinante con dos lineas paralelas proporcionales? Cristina, ¿seguro? Venga, pues este el vector cero. Pues, venga, no tenemos que hacer ninguna operación. Si este vector es el cero... las dos de atrás, por favor, ¿podemos seguir? que nos están grabando, venga. El be por ce, ¿cuánto va a valer este también? Centro de enseñanza, clase de Bachillerato, Madrid, 19/12/91 A (formalidad = baja, audiencia $=$ interlocutor, canal = cara a cara), CREA, 2012.

${ }^{16}$ Es interesante observar que desde sus orígenes las formas tipo vamos, anda, venga se han empleado en contextos que junto al valor etimológico de movimiento presentaban valores apelativos y expresivos. Para consultar algunas de las formas documentadas en los siglos XIV, XV, XVI, XVII, XVIII y XIX, véase Romero Aguilera (2006: 50-54). 
manipular creativamente el contexto, y con ello desproveer a las formas de su significado originario, para, simultáneamente, enriquecerlas con sus propias valoraciones». Destaquemos también que la mayor parte de los marcadores pragmáticos interactivos que hemos sometido al análisis provienen de las formas del subjuntivo ${ }^{17}$ que, como el modo verbal marcado, se corresponde mejor con la subjetividad y la enfatización ${ }^{18}$.

El proceso de subjetivización, concebido como subtipo del proceso general de gramaticalización, conduce a la aparición de los marcadores discursivos con matices significativos diversos que permiten al hablante involucrarse en el evento, codificando al mismo tiempo su propio punto de vista sobre él. El alcance interaccional de los marcadores tipo vamos, venga, vaya, anda no puede pasar desapercibido ante todo si tenemos bien presente que, tal y como quieren las teorías recientes sobre la gramaticalización, la rutinización del uso junto con una codificación o manifestación gramatical explícita abarcan zonas que se presentan como semántica y pragmáticamente importantes en una determinada comunidad de habla.

Resumiendo, el proceso de subjetivización, al quedar en estrecha relación con el de gramaticalización y pragmatización, se basa en la idea de que los términos gramaticalizados son el resultado de la convencionalización de un conjunto de implicaturas conversacionales. Se lo puede ver perfectamente acercándose a la denominada «pragmática diacrónica» que, al estudiar la evolución funcional de distintas clases de operadores, indica de qué modo los cambios que experimentan los signos que transmiten informaciones pragmáticas equivalen a los cambios en las características de la enunciación, en las relaciones que establecen los interlocutores entre sí o/y con respecto al objeto o al entorno de comunicación (Ridrujeo, 2002: 97). Lo que se pone de manifiesto es la actitud personal del emisor, su participación manifiesta orientada siempre a la interacción con el receptor. En este breve estudio la fuente de ejemplos han sido fundamentalmente los marcadores conversacionales de matización apelativo-interjectiva, pero serían igualmente los adverbios argumentativos tipo verdaderamente $^{19}$ los que confirman que los modificadores oracionales llegan a funcionar en un ámbito extraoracional como marcadores del discurso, enfatizando la fuerza ilocutiva de los actos de habla emitidos por los hablantes y modificando el nivel discursivo ${ }^{20}$.

${ }^{17}$ Es así incluso en el caso de vamos que, como demuestra un análisis exhaustivo efectuado por González Ollé (2002, citado por Romero Aguilera, 2006: 50), procede de la primera persona del singular del presente de subjuntivo y no, como suele pensarse, de la primera persona del presente de indicativo del verbo $i r$.

${ }^{18}$ Lo mismo podría decirse del modo imperativo (cuyas formas en español proceden en mayoría del subjuntivo): sus propiedades gramaticales se insertan perfectamente en el ámbito de la subjetividad (recordemos también la naturaleza apelativa del imperativo así como su valor de regulador de interacción comunicativa).

${ }^{19}$ Véase en este sentido a González Manzano (2010).

20 En la misma línea, parece llamativa la adquisición por parte de ciertos adverbios ya existentes de funciones que hasta ahora no venían desempeñado. Siguiendo a Downing Rothwell (1978: 17-20), me refiero a la utilización como modificadores de un número creciente de adverbios ingleses 
En palabras de Traugott (1995: 37), el proceso de subjetivización «refers to a pragmatic-semantic process whereby meanings become increasingly based in the speaker's subjective belief state/attitude toward the proposition, in other words, towards what the speaker is talking about».

Por otra parte, me parece importante señalar que el protagonismo cedido a la expresión de la subjetividad del hablante se traduce a menudo en la presencia de elementos emotivos de los que se tiñen las formas lingüísticas que han pasado por distintas etapas de subjetivización. Así, los marcadores interaccionales, aparte de asumir unas determinadas funciones pragmáticas, pueden transmitir varios significados adicionales. El efecto de sentido que se presentaría como el más típico dentro de los llamados significados adicionales sería, a mi modo de ver, la «emotivización» cuyo alcance dentro de los intercambios comunicativos es básicamente estratégico y regulador ( $\sin$ hacer necesariamente referencia a los estados psico-afectivos reales de los interactantes). Tal vez, estamos ante una aparente paradoja: el principio de cooperación (Grice, 1975) que rige los intercambios comunicativos se fundamenta en el respeto por las reglas que conciernen a los contenidos proposicionales y procedimentales (recuérdense «las máximas de cantidad, cualidad, relación y modalidad»). Los operadores resultantes del proceso de subjetivización en una inmensa mayoría de casos se presentan vacíos de contenido proposicional (de hecho, se los trata con frecuencia como «muletillas conversacionales») y, sin embargo, son ellos los que aseguran una lograda cooperación entre los interactantes, definiendo además el ambiente y el carácter de las dinámicas interaccionales.

\section{CONCLUSIÓN}

El concepto de subjetivización se presenta como un aspecto «iluminador» no solamente desde el punto de vista de la direccionalidad del cambio gramatical que resulta operativo en el caso de numerosísimas formas y estructuras lingüísticas, sino que explica también el origen de innumerables diferencias que, ante todo bajo una óptica comparativa, van registrándose en los usos comunicativos de distintas comunidades de habla. Si muchas de las motivaciones semánticas, referenciales o relacionales, desde una óptica «global», pueden interpretarse como universales ${ }^{21}$, la fuerza con que operan en cada comunidad lingüística puede mostrarse diferente, generando de este modo gramáticas y estilos comunicativos distintos. Obviamente, las interpretaciones interaccionales e interpersonales que se dan de las formas resultantes de procesos

tipo hopefully, thankfully, arguably, regretfully. Los hablantes parecen mostrar cada vez más una predilección acentuada por la matización de una aseveración cualquiera mediante la expresión de la actitud personal.

${ }^{21}$ Pienso, en este momento, ante todo en los principios del face-work, mencionado en la parte introductoria del presente estudio. 
de gramaticalización/pragmatización/ subjetivización deberían interpretarse siempre tomando en cuenta el parámetro de grado o el de tertium comparationis. Si Company Company (2002) sostenía que la variante peninsular del español, en comparación con el español mexicano, se sitúa del lado de mayor «objetividad y distancia» comunicativa, la puesta en relación de los usos comunicativos peninsulares con los propios, por ejemplo, de las comunidades dominadas por el modelo de cortesía negativa (entre ellas, la mayoría de las comunidades anglosajonas) llevaría a una afirmación totalmente opuesta. Teniendo en cuenta la actualización de los operadores conversacionales que sufrieron un marcado proceso de convencionalización sociopragmática o la actualización de las formas nominales de tratamiento (a menudo con un carácter altamente gramaticalizado) $)^{22}$, llegaríamos a la conclusión de que el español peninsular, de acuerdo con el ethos comunicativo dominante, se orienta nítidamente hacia la transmisión de las valoraciones subjetivas sobre la «escena comunicativa», concordando así con el principio de involvement.

\section{BIBLIOGRAFÍA}

BARAN, Marek (2010): Emotividad y convención sociopragmática. Una contribución al estudio del ethos comunicativo de la comunidad hispanohablante peninsular. Łódź: Wydawnictwo Uniwersytetu Łódzkiego.

BARAN, Marek (2012): «Acerca de la recategorización interaccional de los marcadores discursivos». Neophilologica, 24: 21-31.

Brown, Penelope; Levinson, Stephen C. (1978): «Universals in language usage: Politeness phenomena». In: Esther N. Goody [ed.], Questions and Politeness. Strategies in Social Interaction. Cambridge: Cambridge University Press, 56-289.

Brown, Penelope; Levinson, Stephen C. (1987): Politeness. Some universals in language usage. Cambridge: Cambridge University Press.

Company Company, Concepción (2002): «Gramaticalización y dialectología comparada. Una isoglosa sintáctico-semántica del español». DICENDA. Cuadernos de Filología Hispánica, 20: 39-71.

Company Company, Concepción (2004a): «¿Gramaticalización o desgramaticalización? Reanálisis y subjetivización de verbos como marcadores discursivos en la historia del español». Revista de Filología Española, 84, 1: 29-66.

Company Company, Concepción (2004b): «Gramaticalización por subjetivización como prescindibilidad de la sintaxis». Nueva Revista de Filología Hispánica, LII/1: 1-27.

DANEŠ, František (1994): «Involvement with language and in language». Journal of Pragmatics, 22: 251-264.

${ }^{22}$ Formas que se manifiestan también en otras comunidades de habla que comparten la inclinación hacia mecanismos de cortesía positiva [a modo de ejemplo podría citarse el fenómeno de surmarquage appelatif en rumano, descrito por Pop (2006: 24-36)], o el uso recurrente de formas apelativas familiares tipo mon frère, ma sœur, mon fils, mon beau que, en el caso del francés camerunés, caracteriza no sólo la esfera privada, sino que también es propio de las relaciones entre desconocidos (Mulo Farenkia, 2008: 85-107). 
DownING Rothwell, Angela (1978): «La subjetivización del adverbio en el inglés de hoy». Cuadernos de investigación filológica, 4: 17-28.

FinEGAN, Edward (1995): «Subjectivity and subjectivisation: an introduction». In: Dieter STEIN, Susan Wright [eds.], Subjectivity and subjectivisation. Linguistic Perspectives. Cambridge: Cambridge University Press, 1-15.

GonzÁlez Manzano, Mónica (2010): «Subjetivización y unidireccionalidad en la evolución histórica del adverbio verdaderamente». Res Diachronicae, 8: 7-27.

GonZÁlez Ollé, Fernando (2002): «Vamos: un conector coloquial de gran complejidad». In: María Antonia Zorraquino, Estrella Montolío Durán [coords.], Los marcadores del discurso. Teoría y análisis. Madrid: Arco/Libros, 117-135.

GonzÁlez SAnz, Marina (2011): «Proceso de gramaticalización y subjetivización de toma». Res Diachronicae, 9: 51-65.

Grice, Herbert Paul (1975): «Logic and Conversation». In: Peter Cole y Jerry L. Morgan [eds.], Speech Acts. Syntax and Semantics 3. New York: Cornell University Press, 41-58.

Kerbrat-Orecchioni, Catherine (1996): La conversation. Paris: Seuil.

LAKOFF, Robin (1973): «The logic of politeness or minding your p's and q's». In: C. Colum et al. [eds.], Papers from the Ninth Regional Meeting of the Chicago Linguistic Society. Chicago: Chicago Linguistic Society, 292-305.

LAKOFF, Robin (1975): Language and Woman's Place. New York: Harper and Row.

LANGaCKer, Ronald W. (1987): Foundations of Cognitive Grammar. Volume 1, Theoretical Prerequisites. Stanford: Stanford University Press.

LANGACKer, Ronald W. (1990): «Subjectification». Cognitive Linguistics, 1: 5-38.

LANGACKER, Ronald W. (1991): Foundations of Cognitive Grammar. Volume 2, Descriptive Application. Stanford: Stanford University Press.

LANGACKER, Ronald W. (2000): Grammar and Conceptualization (Cognitive linguistics research). Berlin - New York: Mouton de Gruyter.

LeECH, Geoffrey N. (1983): Principles of Pragmatics. London: Longman.

Mulo Farenkia, Bernard (2008) : « Du vocatif au relationnel : Typologie des fonctions pragmatiques des formes de l'adresse au Cameroun ». In: Bernard Mulo FARENKIA [ed.], De la politesse linguistique au Cameroun. Frankfurt am Main - Berlin - Bern - Bruxelles - New York - Oxford, Wien: Peter Lang, 85-107.

NuYTs, Jan J . (2001): «Subjectivity as an evidential dimension in epistemic modal expressions». Journal of Pragmatics, 33: 383-400.

Pop, Liana (2006) : « Peut-on parler de style interjectif ? Le cas du roumain ». Langages, 161: 24-36.

Real Academia Española, Banco De Datos (CREA): Corpus de referencia del español actual. [en línea] http://www.rae.es.

ReYNoso Noverón, Jeanett (2005): «Procesos de gramaticalización por subjetivización: el uso del diminutivo en español». In: David EdDington [ed.], Selected Proceedings of the 7th Hispanic Linguistics Symposium. Somerville, MA: Cascadilla Proceedings Project, 79-86.

RidRUEJo, Emilio (2002): «Cambio pragmático y cambio gramatical». Language Design, 4: 95-111. ROMERo Aguilera, Laura (2006): «La gramaticalización de verbos de movimiento como marcadores del discurso: el caso de vamos». Res Diachronicae, 5: 46-56.

TANNEN, Deborah (1989): Talking voices: Repetition, dialogue, and imagery in conversational discourse. Cambridge: Cambridge University Press.

TraugotT, Elizabeth Closs (1989): «On the rise of epistemic meanings in English: An example of subjectification in semantic change». Language, 65: 31-55.

TraugotT, Elizabeth Closs (1995): «Subjectification in grammaticalisation». In: Dieter SteIN, Susan Wright [eds.], Subjectivity and Subjectivisation. Cambridge: Cambridge University Press, $37-54$. 
TraugotT, Elizabeth Closs (1999): «The rhetoric of counter-expectation in semantic change: A study in subjectification». In: Andreas BlanK and Peter КосH [eds.], Historical semantics and cognition. Berlin - New York: Mouton de Gruyter, 177-196.

TraugotT, Elizabeth Closs; DAsher, Richard B. (2001): Regularity in semantic change. Cambridge: Cambridge University Press. 